\title{
Study on Dynamic Water Environmental Capacity of Fenghuangshan Drinking Water Source Area in Three Gorges Reservoir
}

\author{
S. Y. Liu ${ }^{1}$, Q. D. Zhu², A. F. Zhai ${ }^{1}$, and X. W. Ding ${ }^{1}{ }^{*}$ \\ ${ }^{1}$ Key Laboratory of Regional Energy and Environment Systems Optimization, College of Environmental Science and Engineering, \\ North China Electric Power University, Beijing 102206, China \\ ${ }^{2}$ State Key Laboratory of Hydrology and Water Resources and Hydraulic Engineering Science, Nanjing 210029, China
}

Received 31 March 2021; revised 27 April 2021; accepted 05 June 2021; published online 30 June 2021

\begin{abstract}
Research on water environment capacity is an important part of watershed water environment management. Based on the basic theory of water environment capacity, this study obtained and analyzed the dynamic water environment capacity in Fenghuangshan drinking water source area, Three Gorges Reservoir. In this study, eight water indicators were taken as the indicator object, and the dynamic water environment capacity change range from 2012 to 2017 was permanganate index, biochemical oxygen demand, ferrum, ammonia nitrogen, total phosphorus, anionic surfactant, hexavalent chromium and cuprum, in descending order. The the dynamic water environment capacity of anionic surfactant would increase mainly in pre-flood stage and after storage stage and the other indicators would increase mainly in the end of the flood stage and storage stage. Besides, when the difference between inflow and outflow was positive, the dynamic water environment capacity of anionic surfactant would be reduced and other indicators would be increased. Moreover, the results of time-series analysis introduced showed that this method could be used to predict the change trend of dynamic water environment capacity. Overall, the research in this paper could be a new reference for scientists and decision makers in analyzing, predicting and control the change trend of water environment.
\end{abstract}

Keywords: dynamic water environment capacity, drinking water, Three Gorges Reservoir, time-series analysis, water flow

\section{Introduction}

With the acceleration of economic development and urbanization, China's water environment problems have become more and more serious (Zhou et al., 2017). Research and calculation of water environment carrying capacity is one of the foundations of water environment management (Liu et al., 2012a; Chen et al., 2014; Wang et al., 2015). The specific concept of water environment carrying capacity has not yet reached consensus in academia and the understanding of water environment carrying capacity is mainly divided into two types currently. Broadly speaking, water environment carrying capacity is the ability to support human activities in a certain time and state (Arrow et al., 1996; Wei et al., 2019). Lu et al. (2017) evaluated the water environment carrying capacity of Huaihe River Basin by using the method of analytic hierarchy process and found the significant influencing factors on the water environment carrying capacity was social factors. In a narrow sense, water environment carrying capacity could be defined as the amount of pollutants that the water environment can hold under the specified environmental goals (Cairns, 1998). This paper had adopted the

${ }^{*}$ Corresponding author. Tel.: +86-010-6177-2727.

E-mail address: binger2000dxw@ hotmail.com (X. W. Ding).

ISSN: 2663-6859 print/2663-6867 online

(C) 2021 ISEIS All rights reserved. doi:10.3808/jeil.202100063. narrow concept of water environment carrying capacity and applied in the drinking water source area of Three Gorges Reservoir (TGR). In this situation, water environment capacity could be understood as the sum of dilution capacity and self-purification capacity.

In recent years, many researchers have been studied and analyzed the capacity of water environment in different water areas. Applying different methods to analyze water environment capacity would be simple and effective ways. To determine the capacity of water environmental for metal species, Pesavento et al. (2009) analyzed and summarized several methods, such as separation techniques based on ion exchange (Gerlo et al., 1997) and complexing resins (Pesavento et al., 2003), as well as Donnan membrane technique (Lao et al., 2018). Besides, introducing numerical model has been a common method to calculate water environment capacity. Yan et al. (2011) analyzed the water environment capacity of the Poyang Lake by using statistical models and the results showed that the flooding-proof system of the region is relatively low. Liu et al. (2012b) calculated the water environment capacity values of total phosphorus (TP) in the Baixi watershed area by using the method of Monte Carlo. Moreover, adjusting parameters in water quality model is also an effective way to analyze water environment capacity. $\mathrm{Li}$ et al. (2015) determined the water environment capacity of nitrogen and phosphorus in Jiaozhou Bay using a developed 3D water quality model. This model could reproduce the spatiotemporal 
changes of nutrient concentration effectively. By discussing the methods of how to determine the design flow and degradation coefficient, Li et al. (2010) calculated the water environment capacity of Zhangweinan Canal Sub-basin with 1D water quality model. Overall, along with research continuous, more and more methods and developed models have been introduced in the study of water environment carrying capacity quantification and analysis. However, most studies focus on the calculation and impact of water environment capacity but ignored its dynamic changes. Dynamic water environment capacity can objecttively reflect the water environment capacity and its dynamic change characteristics in the actual state and provide reference for the rational utilization of water environment capacity and water quality assurance.

This study would analyze the original principles of water environment capacity calculation and then obtain its dynamic change relationship. Namely, this study aims to develop a model of dynamic water environment capacity (DWEC) and analyze the impact of water flow on DWEC. The Fenghuangshan drinking water source area in TGR was taken as the application object. Compared with the traditional method, this study can better reflect the dynamic relationship of water indicators and provide an important scientific basis for water environment. Besides, this study introduced the method of time-series analysis (Huppert et al., 2009; Das et al., 2020) to predict the dynamic change trend. The results of this research provide a new scientific and reasonable way to analyze, predict and control water environment capacity of drinking water source area for relevant researchers and government decision makers.

\section{Materials and Methods}

\subsection{Dynamic Water Environment Capacity Model}

In this research, dilution capacity is the amount of pollutants that can be reached the water quality target in the drinking water source area. Self-purification capacity is the amount of pollutants that self-cleaning in the water body. The basic principles and equations of water environment capacity model can be described as follows (Yang et al., 2018):

$W=\left(C_{s}-C_{0}\right) Q+\gamma\left(C_{e}\right) V$

$\gamma\left(C_{e}\right)=K C_{0}$

where, $W$ is the water environment capacity of the drinking water source area, $\mathrm{mg} ; C_{s}$ is the contaminant concentration under water quality target, $\mathrm{mg} / \mathrm{L} ; C_{0}$ is contaminant concentration in the drinking water source area, $\mathrm{mg} / \mathrm{L} ; Q$ is the water flow, $\mathrm{m}^{3} / \mathrm{s}$; $V$ is the volume of water body, $\mathrm{m}^{3} ; \gamma\left(C_{e}\right)$ is the self-net coefficient of contaminant, $K$ is the degradation coefficient of contaminant, $1 / \mathrm{s}$.

The values of $K$ were obtained according to the following Equation (General Administration of Quality Supervision, Inspection and Quarantine of the People's Republic of China, 2010):
$K=10.3 Q^{-0.49}$

Analyzing Equation (1), the water environment capacity of unit river length could be derived. Meanwhile, considering the time, the change amount of water environment capacity in unit river length per time can be obtained as follows:

$\frac{\Delta}{\Delta t} W_{L}=\frac{\Delta}{\Delta t}\left[\left(C_{s L}-C_{0 L}\right) Q_{L}+\gamma\left(C_{e}\right) V_{L}\right]$

where, $W_{L}$ is the water environment capacity of unit river length, $\mathrm{mg} ; C_{s L}$ is the the contaminant concentration under water quality target in unit river length, $\mathrm{mg} / \mathrm{L} ; C_{0 L}$ is contaminant concentration in the drinking water source area per river length, $\mathrm{mg} / \mathrm{L}$; $Q_{L}$ is the water flow in unit river length, $\mathrm{m}^{3} / \mathrm{s} ; V_{L}$ is the volume of water body in unit river length, $\mathrm{m}^{3}$.

Time integral calculation for Equation (3), the DWEC change caused by increase in unit volume can be obtained:

$\Delta W_{L}=\left(C_{s L}-C_{0 L}\right) \cdot \Delta Q_{L}+\gamma\left(C_{e}\right) \Delta V_{L}$

In Equation (4), $\Delta W_{L}$ represents DWEC, and it means that the water environmental capacity change caused by increase in unit volume. $\Delta Q_{L}$ represents the increased water flow in unit river length. $\Delta V_{L}$ represents the increased volume of water body in unit river length. Besides, for the unit river length in unit time, $\Delta Q_{L}=$ $\Delta V_{L}$

\subsection{Time-Series Analysis}

Time-series analysis is a method to forecast future data through analyzing historical data. This study used moving average method to analyze the hydrological data and make prediction. For the observation sequence $\left(y_{1}, y_{2}, \ldots, y_{T}\right)$, the calculation Equation can be described as follows (Onishchenko, 1990):

$M_{t}=\frac{1}{N}\left(y_{t}+y_{t-1}+\quad+y_{t-N+1}\right)$

$M_{t}^{(2)}=\frac{1}{N}\left(M_{t}+M_{t-1}+\quad+M_{t-N+1}\right)$

In Equation (6), $M_{t}$ is the moving average at $t ; N$ is the number of items $(N<T)$, it means the number of calculated sequence $\left(y_{t}, y_{t-1}, \ldots, y_{t-N+1}\right)$. In Equation (7), $M_{t}^{(2)}$ is the second moving average. In data processing, triple centered moving average was used on the original data and this process can be implemented using SPSS.

\section{Case Study}

\subsection{Study Area}

Fenghuangshan drinking water source area, Zigui County, Yichang City, Hubei Province, is located in the upstream of Three Gorges Dam (TGD). The geographic coordinates of wa- 
(a) Location of study area

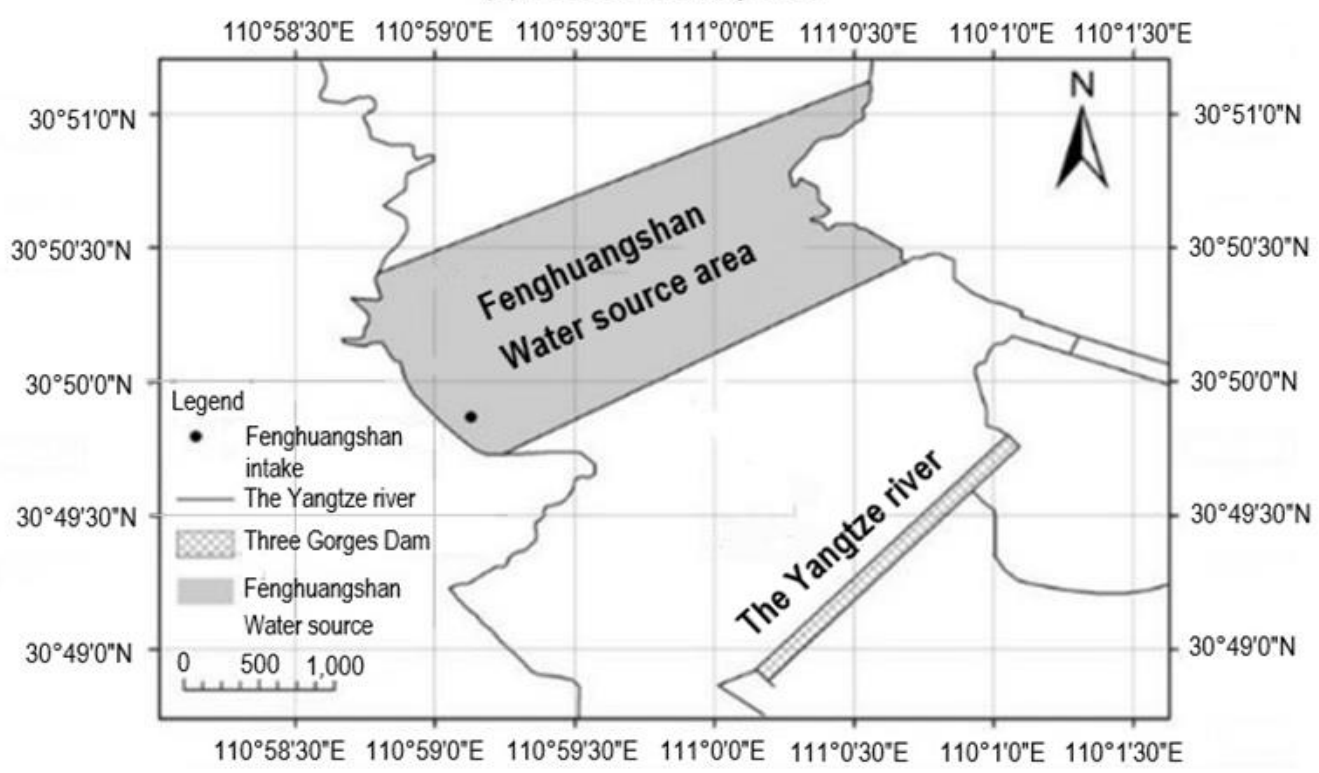

(b) Sectional of study area

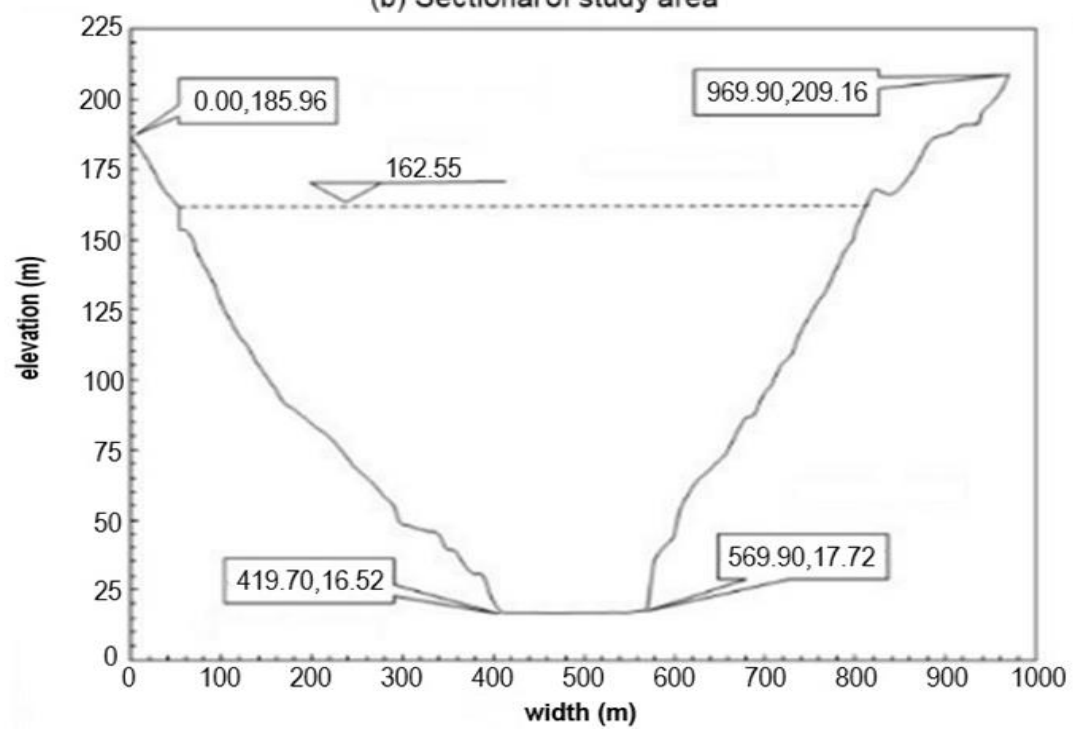

Figure 1. The location (a) and the sectional (b) of Feng-huangshan drinking water source area. (Elevation base: 1985 national elevation benchmarks, China).

ter intake range is $110^{\circ} 59^{\prime} 22.91^{\prime \prime} \sim 111^{\circ} 0^{\prime} 35.73^{\prime \prime} \mathrm{E}, 30^{\circ} 49^{\prime} 38.48^{\prime \prime}$ $\sim 31^{\circ} 50^{\prime} 22.91^{\prime \prime} \mathrm{N}$, including $1000 \mathrm{~m}$ upstream of water intake, $100 \mathrm{~m}$ downstream of water intake and the width of water source area is about $970 \mathrm{~m}$. Figure 1 shows the specific location and the sectional view of study area. Fenghuangshan drinking water source area belongs to river water source and its flow pattern is generally laminar flow. As the main drinking water source of the Zigui County, the water source area supplies water to population of about 40,000 via floating pump boat. To the distance between the study area and the TGD is about $1.5 \mathrm{~km}$, Fenghuangshan drinking water source area has the same hydrology situation with TGR. From 2012 to 2017, the average water level of study area was $162.55 \mathrm{~m}$, the peak of water level was
$174.98 \mathrm{~m}$ (November 2012), and the minimum value was 145.07 $\mathrm{m}$ (June 2013). The average inflow of study area was 12,917 $\mathrm{m}^{3} / \mathrm{s}$ and the average outflow was $12864 \mathrm{~m}^{3} / \mathrm{s}$. The outflow and inflow of the study area were basically at the same levels. For the inflow, the maximum value was $68,175 \mathrm{~m}^{3} / \mathrm{s}$ (July 2012) and the minimum value was $3637 \mathrm{~m}^{3} / \mathrm{s}$ (February 2012). For the outflow, the maximum value was $45,675 \mathrm{~m}^{3} / \mathrm{s}$ (September 2014) and the minimum value was $5,440 \mathrm{~m}^{3} / \mathrm{s}$ (December 2014).

\subsection{Data}

This study chose the permanganate index, TP, ammonia nitrogen $\left(\mathrm{NH}_{3}-\mathrm{N}\right)$, biochemical oxygen demand $\left(\mathrm{BOD}_{5}\right)$, hexa- 

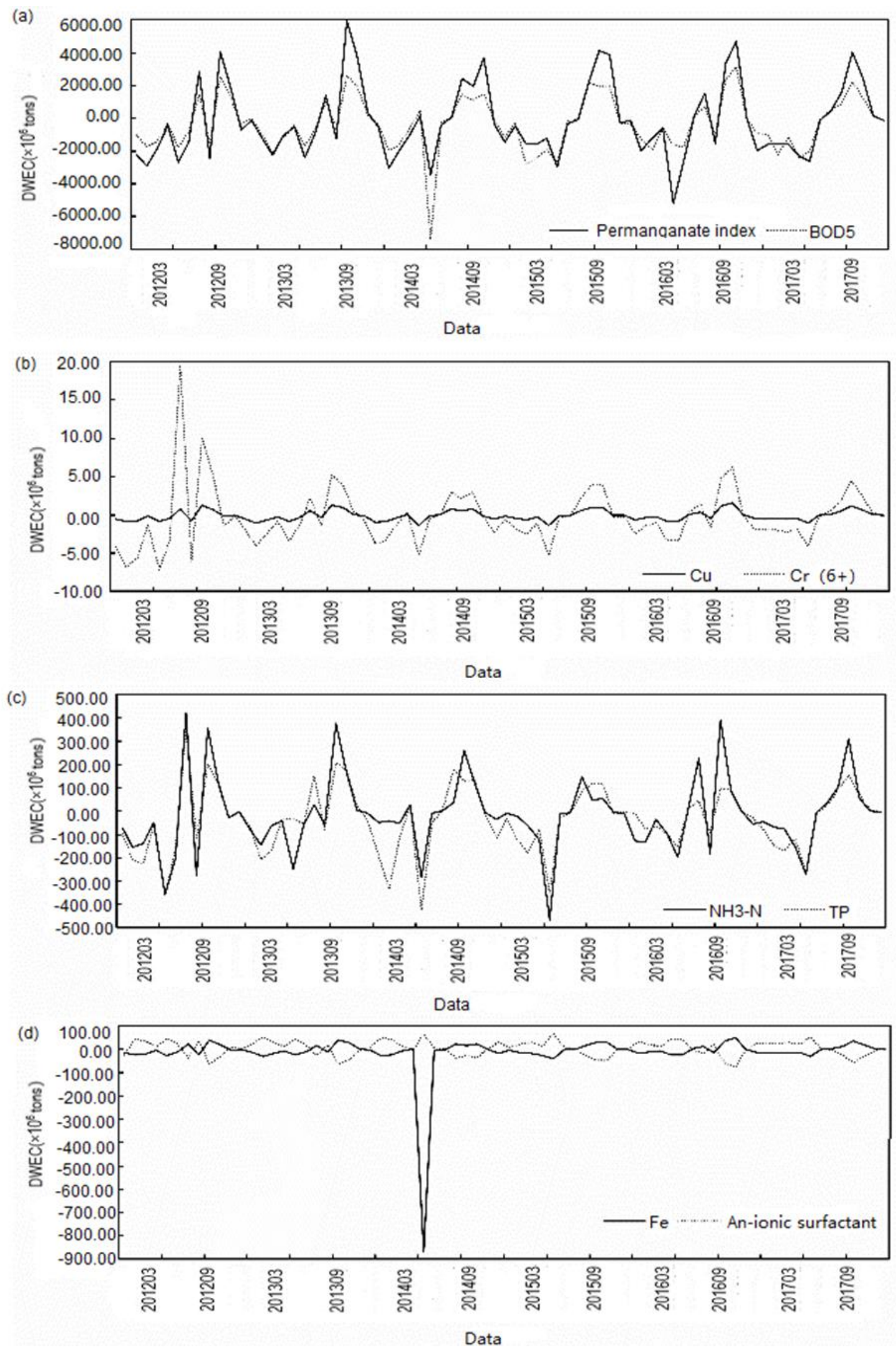

Figure 2. Dynamic water environment capacity from 2012 to 2017. 

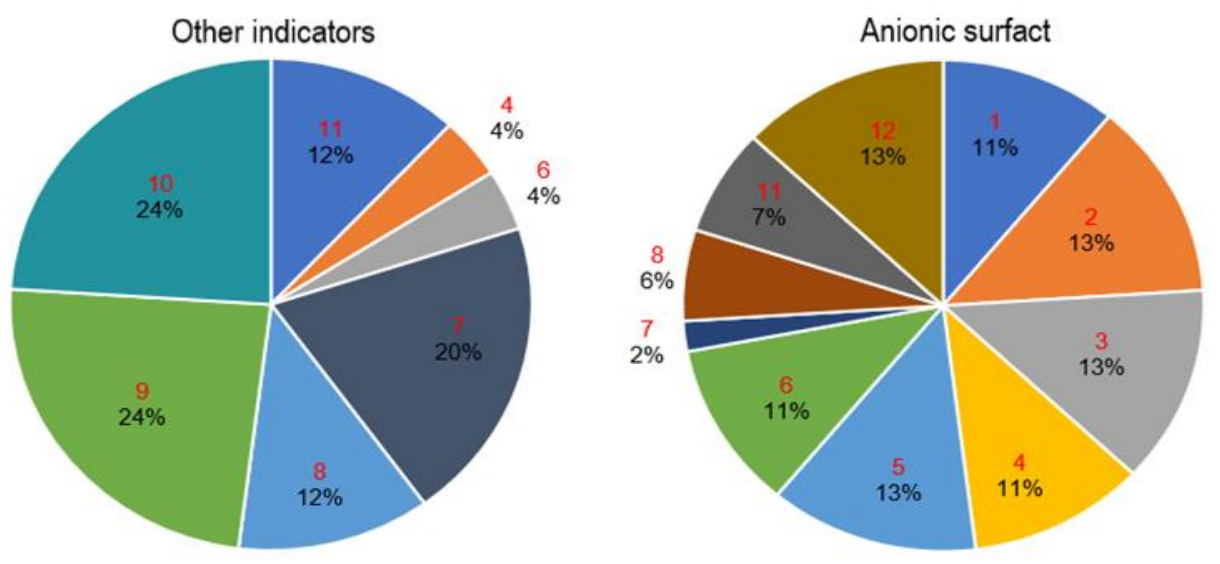

Figure 3. Positive dynamic water environment capacity in each month.

valent chromium $\left(\mathrm{Cr}^{6+}\right)$, ferrum $(\mathrm{Fe})$, cuprum $(\mathrm{Cu})$ and anionic surfactant as the water quality indicators. Monthly concentration from 2012 to 2017 of those water quality indicators were collected from Maoping Hydrological Station, Yichang National Bureau of Statistics. Monthly water inflow and outflow process from 2012 to 2017 were obtained from China Three Gorges Corporation. The dynamic water environment capacity of Fenghuangshan drinking water source area for each water quality index was obtained with consideration of $K$. $C_{s}$ was reference the maximum concentration of water quality index in level III from environmental quality standards for surface water (GB 3838-2002). Values of parameters were shown in Table 1.

Table 1. Values of Parameters (2012 2017)

\begin{tabular}{lllll}
\hline $\begin{array}{l}\text { Water quality } \\
\text { index }\end{array}$ & $\begin{array}{l}\text { Maximum } \\
\text { value } \\
(\mathrm{mg} / \mathrm{L})\end{array}$ & $\begin{array}{l}\text { Minimum } \\
\text { value } \\
(\mathrm{mg} / \mathrm{L})\end{array}$ & $\begin{array}{l}\text { Average } \\
\text { value } \\
(\mathrm{mg} / \mathrm{L})\end{array}$ & $\begin{array}{l}C_{s} \\
(\mathrm{mg} / \mathrm{L})\end{array}$ \\
\hline $\begin{array}{l}\text { Permanganate } \\
\text { index }\end{array}$ & 3.2 & 0.80 & 1.7 & 6.0 \\
$\mathrm{TP}$ & 0.24 & 0.010 & 0.11 & 0.20 \\
$\mathrm{NH}_{3}-\mathrm{N}$ & 0.31 & 0.025 & 0.098 & 1.0 \\
$\mathrm{BOD}_{5}$ & 3.6 & 1.0 & 1.3 & 4.0 \\
$\mathrm{Cr}^{6+}$ & 0.013 & 0.0020 & 0.0020 & 0.050 \\
$\mathrm{Fe}$ & 0.33 & 0.015 & 0.020 & 0.30 \\
$\mathrm{Cu}$ & 0.00050 & 0.00050 & 0.00050 & 1.0 \\
Anionic & 0.025 & 0.025 & 0.025 & 0.20 \\
surfactant & & & & \\
\hline
\end{tabular}

\section{Results and Discussion}

\subsection{Dynamic Water Environment Capacity}

According to the Equation (5), the DWEC values in each month of permanganate index, $\mathrm{BOD}_{5}, \mathrm{Cu}, \mathrm{Cr}^{6+}, \mathrm{NH}_{3}-\mathrm{N}, \mathrm{TP}, \mathrm{Fe}$ and anionic surfactant in Fenghuangshan drinking water source area from 2012 to 2017 were obtained. The results are shown in Figure 2. The negative value of DWEC indicated that the water environment capacity in the drinking water source area was reduced, and a positive DWEC indicated an increasing of water environment capacity. The permanganate index had the maximum amplitude of change and the range value was $[-5170.14$, $5979.43] \times 10^{6}$ tons. The trend of $\mathrm{BOD}_{5}$ was similar to the permanganate index and the former interval was [-7365.35, $3126.97] \times 10^{6}$ tons. The DWEC of $\mathrm{Cu}$ was the most stable and the range was $[-1.35,1.58] \times 10^{6}$ tons. For $\mathrm{Cr}^{6+}$, the range value was $[-7.11,19.56] \times 10^{6}$ tons and the DWEC had a large change in 2012 and then became steady since 2013. The amplitude of change of $\mathrm{NH}_{3}-\mathrm{N}$ and TP was similar and their intervals were $[-465.65,421.27] \times 10^{6}$ and $[-420.88,361.08] \times 10^{6}$ tons, respecttively. For anionic surfactant, the DWEC range was [$78.17,66.90] \times 10^{6}$ tons. The trend of Fe was [-868.06, 46.91] $\times 10^{6}$ tons, it had an abnormal change in May 2014 as the concentration of $\mathrm{Fe}$ was over $0.3 \mathrm{mg} / \mathrm{L}$. However, the trend of $\mathrm{Fe}$ was similar to anionic surfactant when not considering the situation in May 2014.

From 2012 to 2017, the DWEC values of those water quality indicators were positive for 25 months except anionic surfactant and the latter was for 46 months. Figure 3 shows the positive DWEC in each month and its proportion. For anionic surfactant, the positive value would appear throughout the year except September and October, besides the positive value mainly appeared from January to June and December, and the whole percentage was $85 \%$. The other indicators had the same pattern and the positive value mainly appeared in September and October (the sum of percentage was $48 \%$ ), then was July (the percentage was $20 \%$ ). As shown in the Figure 3, the DWEC value of anionic surfactant was increasing mainly in pre-flood stage and after storage stage of the TGR, which in stage the drainage of TGR would be increased and the water level of Fenghuangshan drinking water source area would be declined to $145 \mathrm{~m}$ gradually. On the contrary, the DWEC value of the other indicators was increasing mainly in the end of the flood stage and storage stage, which in stage drainage of TGR would be decreased and the water level would be increased to $175 \mathrm{~m}$.

\subsection{Impact of Water Flow}

Figure 4 shows the relationship between the obtained DWEC of water indicators and water flow in Fenghuangshan drinking water source area from 2012 to 2017. In this study, water flow was divided into inflow and outflow, and the difference between inflow and outflow was $\Delta Q$. This study obtained two 
kinds of trend pattern of DWEC which were anionic surfactant and permanganate index represented the other water indicators, therefore, this section only discussed two situations. As shown in the Figure 4, the values of inflow were essentially the same with outflow. The two kinds of trend pattern of DWEC were affected by water flow. For permanganate index, the DWEC would be changed with water flow genernally. Moreover, the DWEC would be reduced when the outflow was bigger than the inflow, and the value of DWEC would be increased when the inflow was bigger than the outflow. For anionic surfactant, the DWEC of this water indicator has a similar change law with the water flow periodic changed. Furthermore, when the value of outflow was bigger than the value of inflow, the DWEC in the study area would be increased, and the value of DWEC would be reduced while inflow was more than outflow.
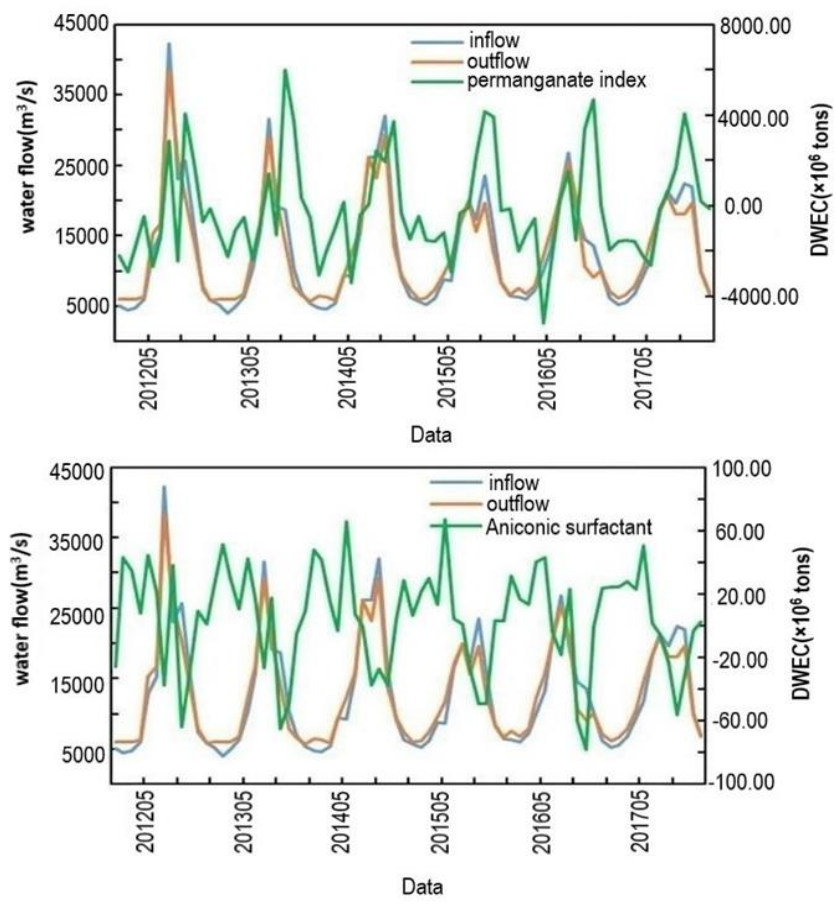

Figure 4. Impact of water flow.

For example, the inflow was smaller than the outflow from January 2017 to May 2017, and the DWEC of permanganate index would be reduced in this period (the value of DWEC changed from $-1,576.41 \times 10^{6}$ to $-2,639.32 \times 10^{6}$ tons), while the DWEC of anionic surfactant would be increased (the value of DWEC changed from $24.63 \times 10^{6}$ to $50.75 \times 10^{6}$ tons). The inflow would be bigger than the outflow from June 2017 to September 2017 and in this period the DWEC of permanganate index would be increased and the final value would reach $4,051.18 \times 10^{6}$ tons. In the meantime, the DWEC of anionic surfactant reduced from $1.90 \times 10^{6}$ tons to $-56.26 \times 10^{6}$ tons. Then the difference between the inflow and outflow would be decreased, the DWEC of permanganate index began to be reduced again and the DWEC of anionic surfactant increased again since October 2017.

\subsection{Time-Series Analysis Prediction}

The method of time-series analysis was used to predict the change trend of DWEC in the drinking water source area. The values of DWEC were obtained according to the Equation (5) based on measured water flow and measured concentration of water indicators. Besides, the method of time-series analysis could not be applied to predict the values of DWEC directly. Therefore, in this study, the change trend of DWEC was obtained by forecasting the future values of water flow and concentration through time-series analysis method. Figure 5 shows the predicted results of water flow and concentration. The predicted results of water flow and concentration were obtained from the original data through the triple centered moving average. The predicted values of water flow were fit for the measured values overall, and the larger error mainly appeared in 2012. The errors between the predicted values and the measured values were decreased from 2013 to 2017 . For the inflow, the mean absolute error was $12.79 \%$ from 2012 to 2017 and $11.23 \%$ from 2013 to 2017, respectively. For the outflow, the mean absolute error was $10.44 \%$ from 2012 to 2017 and $9.36 \%$ from 2013 to 2017, respectively. In summary, the time-series analysis could be used in predicting the trend of water flow. As shown in the Figure 5, the predicted values of anionic surfactant concentrations were equal to the measured values, and the errors appeared in the permanganate index concentration prediction. The main reason for this phenomenon was that the concentrations of anionic surfactant was not changed and always below detection limit, besides, the permanganate index concentrations changed with the water period in TGR. For permanganate index, the mean absolute error between the measured values and predicted values was $16.44 \%$ from 2012 to 2017 . Hence, the method of time-series analysis could be applied to forecast the concentration trend of water indicators. This section taken the DWEC prediction of permanganate index and anionic surfactant as examples and the results were shown in Figure 6. The predicted values of DWEC were obtained by calculating the predicted water flow and concentration according to the Equation (5). The results showed that the predicting trends of DWEC was matched the actual observed trends basically, especially in the midterm of falling period, the end of flood season and storage stage. The mean absolute errors between the predicted values and actual calculated values were $15.29 \%$ and $15.28 \%$ for permanganate index and anionic surfactant in those water periods, respectively. Therefore, using the method of time-series analysis could predict the change trend of DWEC for those water indicators.

\section{Conclusions}

In this study, based on the concept of water environment capacity, a dynamic water environment capacity model was deduced and applied to the Fenghuangshan drinking water source area where in the Yangtze River. Relying on huge historical data including water daily flow and monthly concentration from 2012 to 2017, DWEC of eight water indicators such as permanganate index, TP, $\mathrm{NH}_{3}-\mathrm{N}, \mathrm{BOD}_{5}, \mathrm{Cr}^{6+}, \mathrm{Fe}, \mathrm{Cu}$ and anionic surfactant were obtained. Based on the deduced model of DWEC, results showed that permanganate index had the maximum change am- 

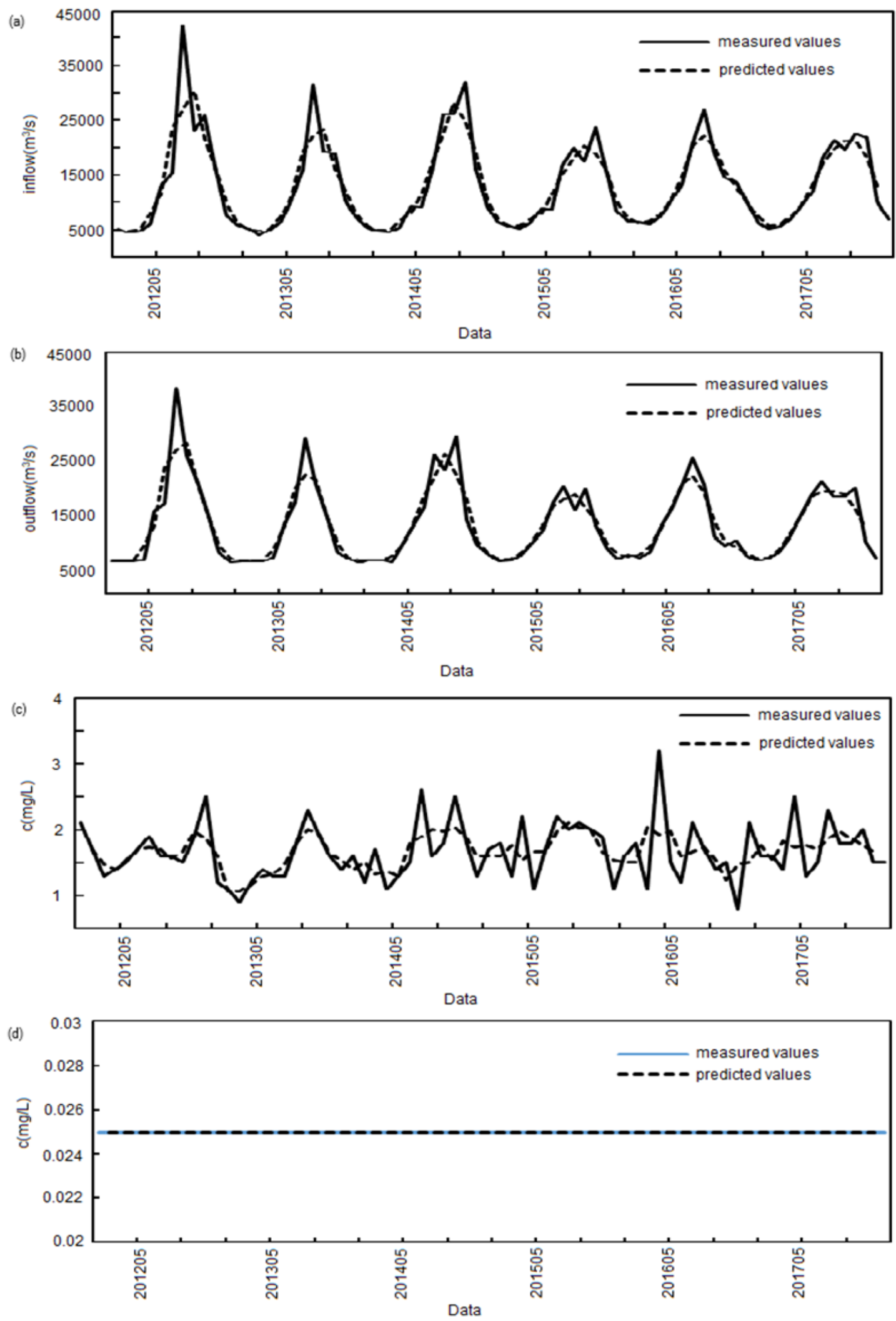

Figure 5. Predicted results of (a) inflow, (b) outflow, (c) permanganate index concentrations and (d) anionic surfactant concentrations. 

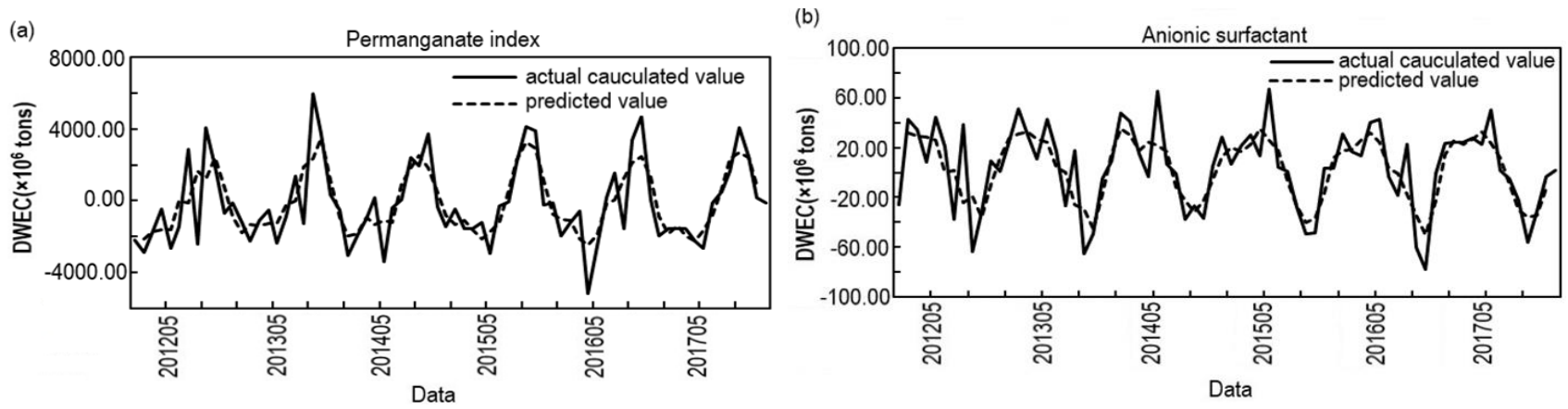

Figure 6. The DWEC trend prediction of (a) permanganate index and (b) anionic surfactant.

plitude and $\mathrm{Cu}$ had the minimum change range. For the other water quality indicators, the change range order was $\mathrm{BOD}_{5}, \mathrm{Fe}$, $\mathrm{NH}_{3}-\mathrm{N}$, TP, anionic surfactant, and $\mathrm{Cr}^{6+}$. According to the results in the study area, the DWEC change trends of water quality indicators studied were identified, and there were two patterns approximately. One is the change trend of water quality indicators including permanganate index, $\mathrm{TP}, \mathrm{NH}_{3}-\mathrm{N}, \mathrm{BOD}_{5}, \mathrm{Cr}^{6+}$, $\mathrm{Fe}$, and $\mathrm{Cu}$, and in this pattern the DWEC would increase mainly in the end of the flood stage and storage stage. The other change trend of DWEC was represented by anionic surfactant, and in this pattern the DWEC would increase mainly in pre-flood stage and after storage stage. Based on analysis of the impact of water flow on those water quality indicators, those two patterns of DWEC change trend were related to the difference between inflow and outflow. When the difference between inflow and outflow was positive, for the pattern of water indicator represented by permanganate index, the DWEC would be increased, however, the DWEC of anionic surfactant would be reduced in this situation. Compared with previous studies, the results of this study showed that the change trend of dynamic water environment capacity is related to water flow. It can better reflect the dynamic change of water environment capacity and provide new ideas for decision makers.

Moreover, to predict the change trend of dynamic water environment capacity, the method of time-series analysis was utilized. In the prediction, concentration of water indicators, water inflow and water outflow were predicted, and thence the predicted DWEC values were obtained. Both mean absolute errors between the predicted values and actual calculated values or permanganate index and anionic surfactant were below $16 \%$ in the mid-term of falling period, the end of flood season and storage stage. In other words, the time-series analysis could be used to predict the change trend of DWEC, basically.

In this study, through the analysis of water indicators, a dynamic water environment capacity model was constructed, and the change trend of dynamic water environment capacity was predicted by the method of time-series analysis. The method of time-series analysis and the construction of dynamic water environment capacity model can be applied to other research areas.

The results in this study showed that the proposed method of calculate DWEC provides a new way for analyzing and forecasting the change trend of water environment capacity in the drinking water source area of TGR. Meanwhile, the introduc- tion of time series methods has further confirmed the scientific rationality of trend prediction. In the time-series analysis prediction, this study ignored some forecast data with large errors, therefore, improving the prediction accuracy of time-series analysis method and applying to the prediction of DWEC would be a key research direction in future research.

Acknowledgements. This research was supported by the National Key Research and Development Plan (2017YFC0404503, 2018YFE0196000 ), and 111 project (B14008). Furthermore, we are very grateful to Wuhan University, Wuhan, China, Guolu Yang; China Three Gorges University, Yichang, China, Daobin Ji; China Three Gorges Corporation, Yichang, China, Zhengfeng Bao for their kind cooperation and discussion at different stages of this study and their timely efforts in supplying the data and information needed for this study. The authors gratefully acknowledge the financial support of the programs and agencies. Finally, authors declare no conflict of interest.

\section{References}

Arrow, K., Bolin, B., Costanza, R., Dasgupta, P., Folke, C., Holling, C.S., Jansson, B., Levin, S., Mäler, K., Perrings, C. and Pimentel, D. (1996). Economic growth, carry capacity, and the environment. Environment and Development Economics, 1(01), 104-110. https:// doi.org/10.1017/S1355770X00000413

Cairns Jr, J. (1998). Assimilative capacity: The key to sustainable use of the planet. Journal of Aquatic Ecosystem Stress and Recovery, 6(4), 259-263. https://doi.org/10.1023/A:1009902127556

Chen, Q., Wang, Q., Li, Z. and Li, R. (2014). Uncertainty analyses on the calculation of water environmental capacity by an innovative holistic method and its application to the Dongjiang River. Journal of Environmental Sciences, 26(09), 1783-1790. https://doi.org/10. 1016/j.jes.2014.06.025

Das, A.P., Thampi, S.M. and Lloret, J. (2020). Anomaly detection in UASN localization based on time deries analysis and fuzzy logic. Mobile Networks and Applications, 25, 55-67. https://doi.org/10.10 07/s11036-018-1192-y

General Administration of Quality Supervision, Inspection and Quarantine of the People's Republic of China (AQSIQ) (2010). Code of Practice for Computation on Allowable Permitted Assimilative Capacity of Water Bodies. GB/T 25173-2010. AQSIQ: Beijing, China.

Gerlo, E. and Gorus, F. (1997). Calibration of ion-exchange HPLC measurements of glycohemoglobin: Effect on interassay precision. Clinical Chemistry, 43(12), 2353-2357. https://doi.org/10.1093/clin chem/43.12.2353

Huppert, T.J., Diamond, S.G., Franceschini, M.A. and Boas, D. (2009). HomER: A review of time-series analysis methods for near-infrared 
spectroscopy of the brain. Applied Optics, 48(10), D280-D298. https://doi.org/10.1364/AO.48.00D280

Lao, M., Companys, E., Weng, L., Puy, J. and Galceran, J. (2018). Speciation of $\mathrm{Zn}, \mathrm{Fe}, \mathrm{Ca}$ and $\mathrm{Mg}$ in wine with the Donnan Membrane Technique. Food Chemistry, 239, 1143-1150. https://doi.org/ 10.1016/j.foodchem.2017.07.040

Li, K., Zhang, L., Li, Y., Zhang, L. and Wang, X. (2015). A threedimensional water quality model to evaluate the environmental capacity of nitrogen and phosphorus in Jiaozhou Bay, China. Marine Pollution Bulletin, 91, 306-316. https://doi.org/10.1016/j.marpol bul.2014.11.020

Li, Y., Qiu, R., Yang, Z., Li, C. and Yu, J. (2010). Parameter determination to calculate water environmental capacity in Zhangweinan Canal Sub-basin in China. Journal of Environmental Sciences, 22 (6), 904-907. https://doi.org/10.1016/S1001-0742(09)60196-0

Liu, D. and Zou, Z. (2012a). Water quality evaluation based on improved fuzzy matter-element method. Journal of Environmental Sciences, 24(7), 1210-1216. https://doi.org/10.1016/S1001-0742(1 1)60938-8

Liu, R.M., Sun, C.C., Han, Z.X., Chen, L., Huang, Q., Chen, Y.X., Gao, S.H. and Shen, Z.Y. (2012b). Water environmental capacity cal- culation based on uncertainty analysis: A case study in the Baixi water-shed area, China. Procedia Environmental Sciences, 13, 1728 -1738. https://doi.org/10.1016/j.proenv.2012.01.166

Lu, Y., Xu, H., Wang, Y. and Yang, Y. (2017). Evaluation of water environmental carrying capacity of city in Huaihe River Basin based on the AHP method: A case in Huai' an City. Water Resources and Industry, 18, 71-77. https://doi.org/10.1016/j.wri.2017.10.001

Onishchenko, V.F. (1990). Estimation of the parameters of the moving average in the case of infinite variance. Theory of Probability \& Its Applications, 34(2), 335-340. https://doi.org/10.1137/1134031
Pesavento, M., Alberti, G. and Biesuz, R. (2009). Analytical methods for determination of free metal ion concentration, labile species fraction and metal complexation capacity of environmental waters: A review. Analytica Chimica Acta, 631, 129-141. https://doi.org/10. 1016/j.aca.2008.10.046

Pesavento, M., Beisuz, R., Alberti, G. and Sturini, M. (2003). Characterization of the sorption of uranium (VI) on different complexing resins. Analytical and Bioanalytical Chemistry, 376, 1023-1029. https://doi.org/10.1007/s00216-003-1951-9

Wang, T. and Xu, S. (2015). Dynamic successive assessment method of water environment carrying capacity and its application. Ecological Indicators, 52, 134-146. https://doi.org/10.1016/j.ecolind.2014. 12.002

Wei, X., Wang, J., Wu, S., Xin, X., Wang, Z. and Liu, W. (2019). Comprehensive evaluation model for water environment carrying capacity based on VPOSRM framework: A case study in Wuhan, China. Sustainable Cities and Society, 50, 101640. https://doi.org/ 10.1016/j.scs.2019.101640

Yan, B., Xing, J., Tan, H., Deng, S. and Tan, Y. (2011). Analysis on water environment capacity of the Poyang Lake. Procedia Environmental Sciences, 10, 2754-2759. https://doi.org/10.1016/j.proenv. 2011.09.427

Yang, G., Lu, J., Luo, W., Zhu, S. and Song, Y. (2018). Discussion of consensus problems for water environmental capacity. Journal of North China University of Water Resources and Electric Power (Natural Science Edition), 39(4), 1-6. (In Chinese)

Zhou, X.Y., Lei, K., Meng, W., Khu, S., Zhao, J., Wang, M. and Yang, J. (2017). Space-time approach to water environment carrying capacity calculation. Journal of Cleaner Production, 149, 302-312. https://doi.org/10.1016/j.jclepro.2017.02.110 